\title{
Non-apoptotic functions of caspases in myeloid cell differentiation
}

\author{
Stéphanie Solier ${ }^{1}$, Michaela Fontenay ${ }^{2,3}$, William Vainchenker ${ }^{1}$, Nathalie Droin ${ }^{1}$ and Eric Solary ${ }^{\star, 1,4}$
}

Subtle caspase activation is associated with the differentiation of several myeloid lineages. A tightly orchestrated dance between caspase-3 activation and the chaperone HSP70 that migrates to the nucleus to protect the master regulator GATA-1 from cleavage transiently occurs in basophilic erythroblasts and may prepare nucleus and organelle expel that occurs at the terminal phase of erythroid differentiation. A spatially restricted activation of caspase-3 occurs in maturing megakaryocytes to promote proplatelet maturation and platelet shedding in the bloodstream. In a situation of acute platelet need, caspase-3 could be activated in response to IL-1 $\alpha$ and promote megakaryocyte rupture. In peripheral blood monocytes, colony-stimulating factor-1 provokes the formation of a molecular platform in which caspase-8 is activated, which downregulates nuclear factor-kappa B (NF- $\kappa$ B) activity and activates downstream caspases whose target fragments such as those generated by nucleophosmin (NPM1) cleavage contribute to the generation of resting macrophages. Human monocytes secrete mature IL-1 $\beta$ in response to lipopolysaccharide through an alternative inflammasome activation that involves caspase-8, a pathway that does not lead to cell death. Finally, active caspase- 3 is part of the proteases contained in secretory granules of mast cells. Many questions remain on how these proteases are activated in myeloid cell lineages, which target proteins are cleaved, whereas other are protected from proteolysis, the precise role of cleaved proteins in cell differentiation and functions, and the link between these non-apoptotic functions of caspases and the death of these diverse cell types. Better understanding of these functions may generate therapeutic strategies to control cytopenias or modulate myeloid cell functions in various pathological situations.

Cell Death and Differentiation (2017) 24, 1337-1347; doi:10.1038/cdd.2017.19; published online 17 February 2017

\section{Facts}

- Caspase-3 is transiently activated during erythroid differentiation and cleaves proteins that may prepare expel of mitochondria and enucleation by reticulocytes.

- The key erythroid transcription factor GATA-1 is protected by the chaperone HSP70 that migrates to the nucleus at the onset of caspase activation. The deregulation of this process account for anemia in myelodysplastic syndromes and $\beta$-thalassaemia.

- Caspase-3 activity could be differentially involved in a thrombopoietin-dependent and a thrombopoietin-independent mode of platelet production by megakaryocytes

- Colony-stimulating factor 1 activates in monocytes the formation of a molecular platform in which caspase-8 is activated. This protease and downstream enzymes contribute to the generation of resting macrophages.

- Active caspase-3 is part of the proteases in mast cell secretory granules.

\section{Open Questions}

- How caspases are activated in erythroid cells and megakaryocytes in response to erythropoietin and thrombopoietin, respectively?
- What are the functions of proteins cleaved by caspases in erythroid cells, megakaryocytes and CSF-1-treated monocytes undergoing differentiation?

- Could we manipulate therapeutically caspase activity to promote some lineage differentiation or modulate macrophage polarization?

The highly regenerative hematopoietic tissue, which produces approximately one trillion cells every day within a human adult bone marrow, is viewed as a hierarchical system with hematopoietic stem cells (HSCs) at the apex. In addition to self-renewing, these multipotent cells give rise to all blood cell lineages through generating a pool of oligopotent progenitor cells that undergo a gradual fate restriction and finally assume the identity of a mature cell circulating in the blood. ${ }^{1}$ This roadmap was recently challenged by the results of single cell and family tracing analyses (Figure 1)..$^{2-5}$ Whatever the detailed routes of lineage development, apoptosis is part of the process as T-cell maturation includes the eradication of $\sim 98 \%$ of thymocytes, ${ }^{6}$ autoreactive B-lymphocytes are eliminated in the bone marrow ${ }^{7}$ and loss of function in the apoptotic cascade alters hematopoietic tissue development while increasing cancer susceptibility. ${ }^{8}$

The maintenance of homeostatic cell numbers implicates that the continuous removal of ageing mature cells matches

\footnotetext{
${ }^{1}$ Inserm U1170, Université Paris-Sud, Faculté de Médecine Paris-Sud, Gustave Roussy, Villejuif, France; ${ }^{2}$ INSERM U1016, Institut Cochin, Paris, France; ${ }^{3}$ Assistance Publique-Hôpitaux de Paris, Service d'Hématologie Biologique, Hôpitaux Universitaires Paris Centre, Paris, France and ${ }^{4}$ Department of Hematology, Gustave Roussy, Villejuif, France

*Corresponding author: E Solary, Department of Hematology, INSERM U1170, Gustave Roussy, 114 rue Edouard Vaillant, Villejuif F-94805, France. Tel: +33 1421151 58; Fax: +33 1421152 40; Email: eric.solary@gustaveroussy.fr

Received 30.11.16; revised 06.1.17; accepted 16.1.17; Edited by E Arama; published online 17.2.17
} 


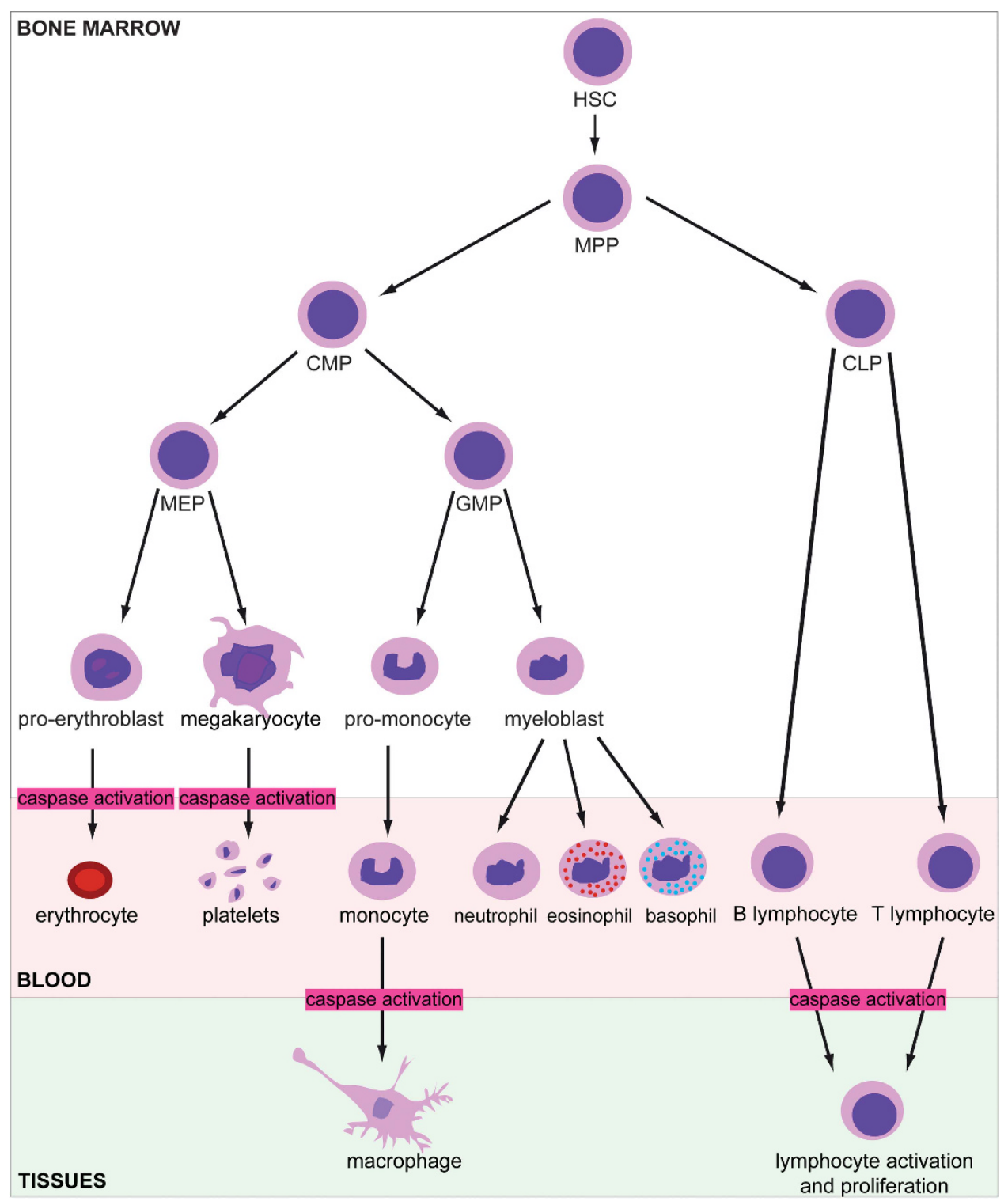

Figure 1 Currently prevalent scheme of hematopoiesis, showing in red the differentiation steps in which caspase activity is involved. CLP, common lymphoid progenitor; CMP, common myeloid progenitor; GMP, granulocyte-monocyte progenitor; HSC, hematopoietic stem cell; MEP, megakaryocyte-erythroid progenitor; MPP, hematopoietic multipotent progenitor

with the production of new cells. Apoptotic caspases are involved in the removal of a number of aged or altered blood cells, these dying cells being cleared by macrophages of the liver, spleen and bone marrow. Apoptosis is the final stage of the short neutrophil and eosinophil life span. ${ }^{9,10}$ Erythrocytes typically undergo senescence and are cleared by the reticuloendothelial system after $100-120$ days. ${ }^{11}$ These cells may also enter a suicidal death process called eryptosis that could involve caspases despite the lack of mitochondria and Apaf-1 adaptor molecule. ${ }^{12}$ Even platelets, which are anuclear cytoplasmic fragments with a 10-days life span, are programmed to die through a caspase-dependent apoptotic process that is activated when $\mathrm{Bcl}-\mathrm{X}_{\mathrm{L}}$ expression declines. ${ }^{13}$

Behind apoptotic caspases, inflammatory caspases can be activated in progenitors ${ }^{14}$ and mature ${ }^{15}$ hematopoietic cells when pattern-recognition receptors interact with pathogen- or damage-associated molecular patterns. This interaction promotes the formation of inflammasomes in which the cytokines interleukin- $1 \beta$ and interleukin- 18 are cleaved to be activated and released to eventually promote non-apoptotic inflammatory cell deaths such as pyroptosis and necroptosis. ${ }^{16}$ These events interfere with emergency hematopoiesis in response to systemic infections and could drive clonal expansion in myelodysplastic syndromes (MDS). ${ }^{17}$ Caspases are also positive and negative regulators of T-cell, B-cell and NK-cell proliferation and activation (Figure 1), ${ }^{18,19}$ as they contribute to NF- $k B$ activation, ${ }^{20}$ cytokine production and apoptosis.

Finally, caspases exert subtle non-apoptotic, non-inflammatory functions in the differentiation of several myeloid lineages. These functions are the focus of this review that 
shows that low-level and transient enzyme activity, chaperoning of proteins whose cleavage would lead to cell death and spatial restriction of activated caspases distinguish caspase activation in differentiating and dying cells.

\section{Caspases in Erythroid Cell Differentiation}

According to the prevalent scheme of hematopoiesis, multipotent progenitors (MPP) derived from HSCs give rise to intermediate lineage-restricted progenitors, including common myeloid progenitors (CMP) that generate both granulocyte-macrophage (GMP) and megakaryocyte (MK)-erythroid progenitors (MEP; Figure 1). The later progenitors give rise to unipotent erythroid progenitors, with colony assays distinguishing early burst-forming unit - erythroid (BFU-E) from later colony-forming unit - erythroid (CFU-E) progenitors. ${ }^{21}$ The earliest morphologically recognizable erythroid precursor is the proerythroblast, which undergoes successive mitosis, each of them producing a morphologically distinct population of erythroblasts, beginning with proerythroblasts and followed by basophilic, polychromatic, and orthochromatic erythroblasts that expel their organelles and nuclei to generate reticulocytes. This ordered differentiation process is accompanied by decreases in cell size, enhanced chromatin condensation, progressive hemoglobinization and marked changes in membrane. ${ }^{22}$

Synergistically with stem cell factor (SCF), erythropoietin (Epo) regulates red cell production rate through rescuing a number of erythroid progenitors and early precursors from caspase-mediated apoptosis (Box 1). Epo also positively regulates erythropoiesis by stimulating proliferation and differentiation of erythroid progenitors through upregulation of the zinc finger hematopoietic transcription factor, GATA-1 (GATA-binding factor 1). Neither SCF nor Epo are needed for late steps of erythroid differentiation, from polychromatic erythroblasts to reticulocytes.

While the apoptotic function of caspases is required for the negative regulation of erythroid cell differentiation, the transient activation of caspase-3 and possibly other caspases is required for normal erythroblast maturation (Figures 1, 2a and $3 a$,Table 1). ${ }^{23-26}$ This assertion is based on the ability of pan-caspase inhibitors to block erythroid development at the basophilic stage of maturation, the demonstration of procaspase- 3 cleavage in erythroid precursors, and the cleavage of caspase-specific peptide substrates in differentiating erythroid cells (Table 1). ${ }^{25-27}$ Caspase-3 knock-out mouse models demonstrate distinct phenotypes, depending on their genetic background ${ }^{28,29}$ and the ability of one of them to reach adulthood without defective erythropoiesis questioned the role of caspase-3 in erythroid differentiation. ${ }^{29}$ However, redundancies exist between caspases and ablation of caspase-3 by small interfering RNA could block erythropoiesis in a large fraction of the erythroblasts in culture. ${ }^{24}$

Several proteins are cleaved by caspases in differentiating erythroblasts (Table 1), including the kinases ROCK-1 and MEKK1, lamin B, Acinus, ICAD (Inhibitor of caspase-activated DNase), and hnRNP K (heterogeneous nuclear ribonucleoprotein K) ${ }^{25,26,30-33}$ ROCK-1 activating cleavage occurs when the SCF/C-KIT-mediated activation of the Rho/RACK signaling pathway is fading, due to the downregulation of $\mathrm{c}-\mathrm{KIT}$, and active ROCK-1 phosphorylates the light chain of myosin II. ${ }^{31}$ Another kinase cleaved and activated by caspase- 3 is MEKK1 that, in turn, activates MEK6/p38a pathway. ${ }^{30}$ How these kinases contribute to erythroid differentiation remains unknown. Caspases may be involved in the timely controlled lost of organelles that characterizes terminal erythroid differentiation, for example the cleavage of hnRNP $\mathrm{K}$ induces the synthesis of reticulocyte 15-lipooxygenase (r15-LOX) that is needed for the degradation of mitochondria in reticulocytes. $^{33}$

One of the characteristic features of erythropoiesis in mammals is a dramatic nuclear condensation observed in orthochromatic erythroblasts and the subsequent extrusion of the nucleus. ${ }^{34}$ shRNA knockdown of caspase-3 in human erythroid cells significantly reduces the number of enucleated cells. ${ }^{24}$ DNase $11 a^{35}$ and Acinus ${ }^{26}$ could be the endonucleases responsible for chromatin condensation. Recently, caspase-3 was shown to be required for transient and repeated nuclear opening that occurs in differentiating erythroid cells until just before enucleation, are tightly linked with the cell cycle and permit the selective release of core and linker histones in the cytoplasm where they aggregate around the nuclear opening before being rapidly degraded by the proteasome machinery. ${ }^{36}$ Pharmacologic or genetic loss of function of caspase-3 blocks nuclear opening and nuclear condensation, restores nuclear histone $\mathrm{H} 2 \mathrm{~B}$, repairs nuclear openings and abrogates new opening formation. ${ }^{37,38}$ Nuclei expelled from

\section{Box 1 Epo regulates red cell production rate through rescuing erythroid progenitors and early precursors from apoptosis}

Induction of $\mathrm{Bcl}-\mathrm{X}_{\mathrm{L}}$ expression by EpoR-activated STAT5 is a major survival pathway in erythroblasts, ${ }^{113-115}$ which is associated with the ERK-induced degradation of the pro-apoptotic protein Bim. ${ }^{116}$ An intracellular Spi2A serpin, which inhibits lysosomal cathepsins, is another Epo/STAT5 cytoprotective target that protects erythroblasts from radical oxygen species toxic effects. ${ }^{117}$ Splenic early erythroblasts could also negatively regulate their own survival by co-expressing the death receptor Fas and its ligand, FasL. This regulatory loop accelerates the response to hypoxic stress that otherwise requires a delay for the maturation of Epo-responsive progenitors mature into red cells. ${ }^{118,119}$ Fas ligation results in the activation of caspase- 8 , then caspase-3, and the cleavage of SCL/Tal- $1^{120}$ and GATA- $1^{118}$ transcription factors whose inactivation induces a maturation arrest at the basophilic erythroblast stage and cell death by apoptosis. 

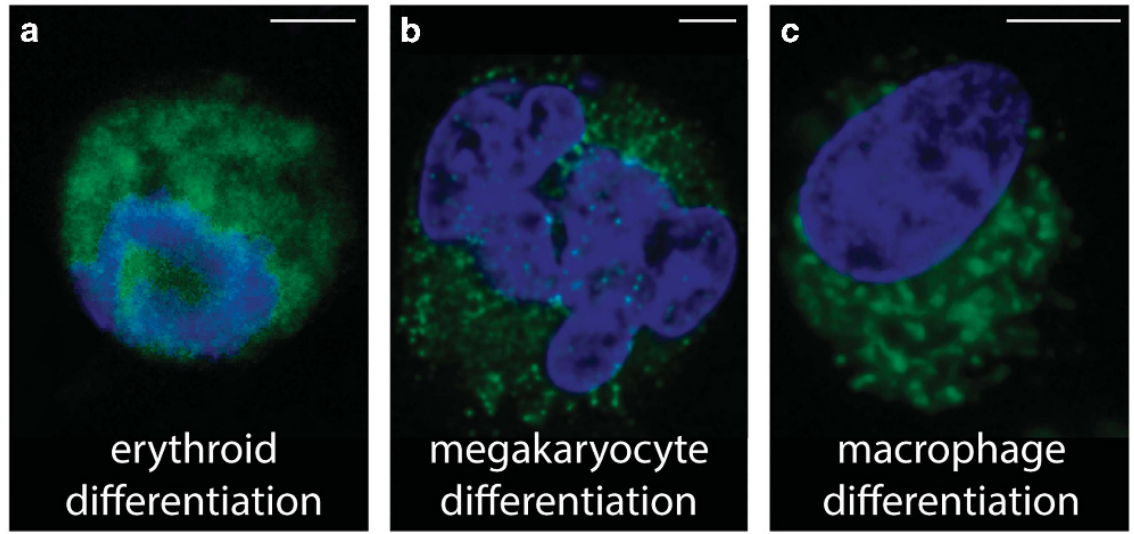

Figure 2 Caspase activation during differentiation of the indicated lineages. Active caspase-3 (green; Cell Signaling antibody 9664; 1:250 dilution) and nuclear chromatin (DAPI, blue) staining of (a) K562 human leukemic cells treated with $30 \mu \mathrm{M}$ haemin for 4 days; (b) Megakaryocytes sorted on CD41a and CD42 expression from cultures of primary human ${\mathrm{CD} 34^{+}}^{+}$cells in serum-free medium with $10 \mathrm{ng} / \mathrm{ml} \mathrm{TPO}$ and $5 \mathrm{ng} / \mathrm{ml} \mathrm{Stem} \mathrm{Cell} \mathrm{Factor} \mathrm{for} 5$ days; (c) CD14 $4^{+}$peripheral blood monocytes treated with $100 \mathrm{ng} / \mathrm{ml}$ Colony-Stimulating Factor 1 for 3 days. Confocal images were acquired on a Leica SPE Confocal system. The immunofluorescence staining protocol details are found in Solier et al. ${ }^{112}$ Scale bar, $5 \mu \mathrm{m}$

erythroid precursor cells quickly expose phosphatidylserine on their surface and are engulfed by macrophages. ${ }^{39}$

Importantly, the transcriptional factor GATA-1, which is degraded by caspases in erythroid cells undergoing apoptosis upon cytokine starvation or exposure to death receptor ligands, ${ }^{40}$ remains uncleaved in differentiating erythroblasts (Figure 3a). GATA-1 plays a central role in Epo-mediated upregulation of genes involved in erythroid cell differentiation, including EpoR, a-globin and glycophorin $\mathrm{A}_{\text {genes }}{ }^{41}$ and in erythroid cell survival, mainly $\mathrm{BCl}-\mathrm{X}_{\mathrm{L}}{ }^{42}$ The chaperone protein HSP70 translocates to the nucleus at the onset of caspase activation to physically interact with, and protect GATA-1 from caspase-mediated proteolysis (Figure 3a). GATA-1 is cleaved by caspase- 3 when HSP70 is downregulated in erythroid precursors cultured in the presence of Epo, which leads to the downregulation of $\mathrm{Bcl}-\mathrm{X}_{\mathrm{L}}$ and cell death by apoptosis. Epo starvation induces the nuclear export of Hsp70, exposing GATA-1 to caspase-mediated proteolysis. ${ }^{43}$ Deregulation of the interplay between HSP70, GATA-1 and caspases may account for the anemia that develops in some MDS $^{44,45}$ and $\beta$-thalassaemia ${ }^{46}$ (Box 2). At the end of erythroid differentiation, GATA-1 expression level and activity decrease. ${ }^{47}$ To finetune GATA-1 expression, another chaperone, HSP27 binds in its p38-phosphorylated form to acetylated GATA-1 to promote its ubiquitination and proteasomal degradation. ${ }^{48}$

\section{Caspases in Proplatelet Formation and Platelet Release}

Thrombopoietin (TPO) interacting with its receptor MPL promotes the conversion of HSCs and multipotent progenitors into MK progenitors ${ }^{2,4}$ (Table 1) whose terminal differentiation includes a switch from mitosis to endomitosis to generate polyploid cells. At the end of polyploidization, MK undergo cytoplasmic maturation with important changes in cytoskeleton organization leading to the release of $10^{11}$ platelets per day in the bloodstream. Platelet biogenesis involves the fragmentation of the MK cytoplasm through cytoplasmic extensions called proplatelets that arise from the elongation of the internal membrane powered by microtubule forces. These proplatelets brake into the vascular space due to the blood shear forces and further fragment into preplatelets and platelets in the bloodstream. These cells repair vascular injuries and prevent excessive bleeding. Their generation is tightly controlled by exogenous and endogenous factors.

The role of caspases in MK differentiation remains a controversial issue (Figures 1, $2 \mathrm{~b}$ and $3 \mathrm{~b}$,Table 1). ${ }^{49}$ It was initially reported that MK died by apoptosis and that the peak of platelet production by $\mathrm{MK}$ corresponded to the onset of apoptosis. ${ }^{50}$ The thrombocytopenia observed in mice overexpressing $\mathrm{Bcl}-2^{51}$ or deficient in $\mathrm{Bim}^{52}$ further argued for an apoptotic component in proplatelet formation. Furthermore, proplatelet formation is impaired in murine MK overexpressing $\mathrm{Bcl}-\mathrm{X}_{\mathrm{L}}$ under control of the platelet factor 4 (PF4) promoter $^{53}$ and in human MK cultured with the pan-caspase inhibitor Z-VAD-fmk. ${ }^{54,55}$ Finally, the presence of active caspase-3 in discrete parts of maturing MK cytoplasm suggested that spatially restricted apoptosis could facilitate platelet shedding (Figure 2b). This punctuated distribution of active caspase-3 contrasted with the diffuse staining observed in apoptotic MK (Table 1). ${ }^{55}$

Amplification of this spatially restricted caspase activation could have explained thrombocytopenia that occurs in patients exposed to toxic, infectious or immune insults as well as in MDS, leading to MK apoptosis before platelet release. ${ }^{56}$ Accordingly, an autosomal dominant form of thrombocytopenia was detected in a family with a constitutive variant of cytochrome $c$ (G41S) with enhanced ability to activate caspases, which could accelerate the release of platelets in the bone marrow rather than the bloodstream. ${ }^{57}$ In a cell-free system, G41S-increased caspase activation was observed only at low cytochrome $c$ concentrations, suggesting that differentiation-induced caspase activation involves the release of low cytochrome $c$ concentrations in the cytosol, with higher concentrations released in stressful conditions triggering MK apoptosis. However, caspase-9 may be dispensable for these processes, which questions the target of cytochrome $c$ when released in the cytosol of mature MKs. ${ }^{58}$ 
a
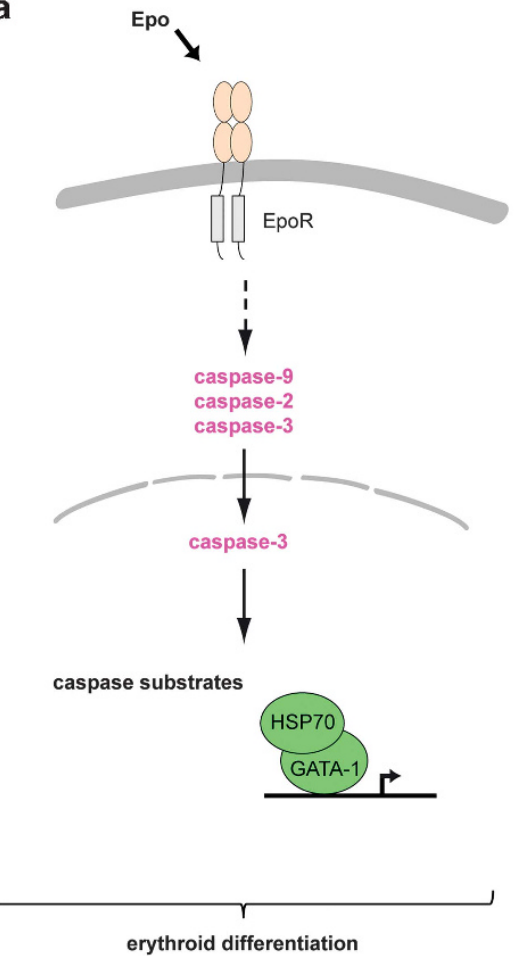

c

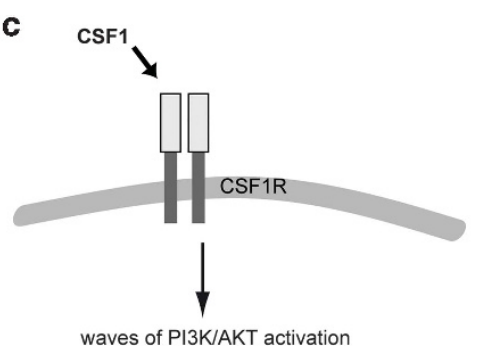

waves of PI3K/AKT activation

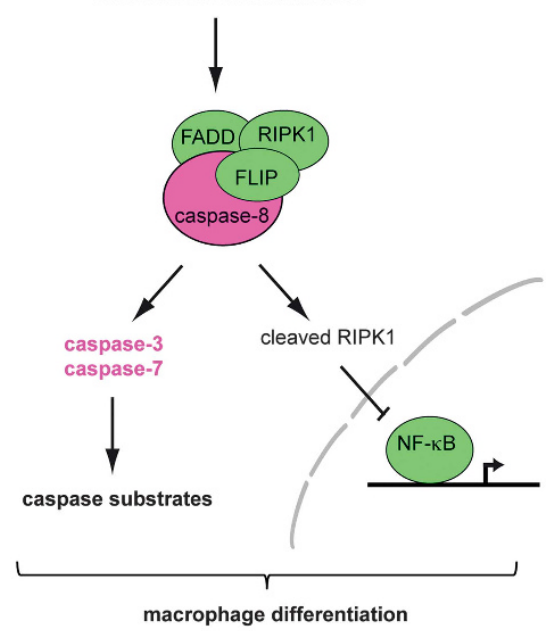

b
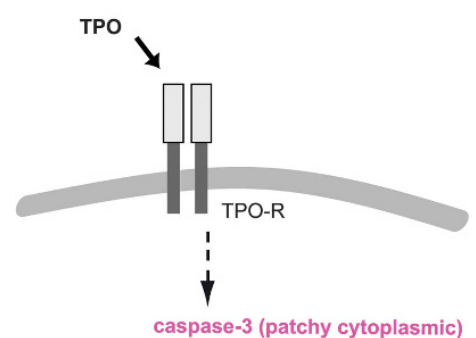

caspase substrates

proplatelet formation

Figure 3 Schematic representation of the role of caspases during erythroid differentiation (a), proplatelet formation (b) and CSF-1-induced macrophage differentiation (c)

Both $\mathrm{Mcl}-1$ and $\mathrm{BCl}-\mathrm{X}_{\mathrm{L}}$ are required to keep Bak and Bax in check in MK. ${ }^{59-61}$ The simultaneous deletion of Bak and Bax, which protects MK from apoptotic stimuli, does not alter thrombopoiesis at steady state or under conditions of stress. ${ }^{60,62}$ It remains unclear how a restricted or localized apoptosis-like process that activates caspases is activated in mature MK and used for platelet shedding, independently of Bak and Bax.

A role of the extrinsic pathway to caspase activation has been suspected as the number of cultured MK that form proplatelets increased when exposed to Fas Ligand or agonistic Fas antibodies or TNF-related apoptosis-inducing ligand (TRAIL), or delivery of a recombinant active form of caspase-8. ${ }^{54,63}$ Accordingly, decreased TRAIL expression in the context of immune thrombocytopenia could reduce proplatelet formation. ${ }^{64}$ However, some of these results were obtained in megakaryoblastic cell lines exposed to the poorly specific caspase inhibitor Z-VAD-fmk and further studies showed that, if a FasL-responsive caspase-8-mediated extrinsic apoptosis pathway was operative in MK, this pathway was dispensable for platelet production. ${ }^{65}$ Altogether, the restricted or localized apoptosis-like process that may activate caspases in mature MK to promote platelet shedding is independent of the extrinsic pathway.

If there is no strong argument to sustain the initial hypothesis that mature MK may undergo classical apoptosis to promote platelet shedding, caspases could be activated in mature MK and promote platelet release independently of any cell death program, defining a new, non-apoptotic function of these enzymes. A recent report suggested that endoplasmic 
reticulum stress could be responsible for their activation. ${ }^{66}$ Identification of caspase targets that are cleaved in mature MK would be a convincing evidence to support the hypothesis that caspase activation is required for platelet shedding and provide insights on how the localized activation of caspases contributes to platelet formation. One of these targets could be the antiapoptotic protein livin that belongs to the inhibitor of apoptosis proteins (IAP) family. ${ }^{67}$ Cleavage of gelsolin and poly adenosine diphosphate (ADP)-ribose polymerase (PARP) was also detected. ${ }^{55}$

Importantly, MK maturation and platelet biogenesis can occur independently of TPO in situations of acute platelet need. ${ }^{68}$ This interleukin-1 alpha driven, TPO-independent mechanism of platelet production, which yields the rapid release of $\sim 20$-fold higher numbers of platelets as compared with the classical mechanism of proplatelet formation, involves the activation of caspase-3 that reduces plasma membrane stiffness through dysregulating tubulin expression, with an oversupply of $\beta 1$-tubulin. ${ }^{68}$ This mechanism is clearly distinct from the tightly regulated changes in the cytoskeleton that lead to TPO-dependent platelet formation. The balance between TPO and IL-1 $a$ may determine the cellular programming of MK for thrombopoiesis in response to acute and chronic platelet needs.

Platelets themselves are anuclear cytoplasmic fragments that activate a cell autonomous, intrinsic caspase-dependent apoptotic program when $\mathrm{Bcl}-\mathrm{X}_{\mathrm{L}}$ expression declines with ageing. ${ }^{13,49}$ The major dose-limiting toxicity of the $\mathrm{BH} 3$ mimetic drug Navitoclax that inhibits several antiapoptotic proteins including $\mathrm{Bcl}-\mathrm{X}_{\mathrm{L}}$ is thrombocytopenia ${ }^{69}$ while $\mathrm{ABT}$ -199, a Bcl-2-specific BH3 mimetic, has no significant effect on platelet counts. $^{70}$

Finally, platelets demonstrate hemostatic and prothrombotic functions through their ability to adhere and aggregate at sites of vascular injury and to support blood coagulation. The conversion of activated platelets to a procoagulant state is associated with specific biochemical and morphologic changes, some of which being similar to those occurring in apoptotic cells, including exposure of phosphatidylserine at the cell surface, membrane contraction, blebbing and microvesiculation. Upon stimulation with various physiological agonists, the formation of procoagulant platelets involves a calcium-dependent but caspase-independent pathway. ${ }^{71}$ In murine platelets, caspase-12, an enzyme localized at the cytoplasmic surface of the MK endoplasmic reticulum was involved in agonist-induced integrin activation in platelets, suggesting a non-apoptotic function of the enzyme that would need further investigation. ${ }^{72}$

\section{Caspases in Monocyte Differentiation into Macrophages}

The development of circulating blood monocytes involves the growth factor receptor CSF-1 R (colony-stimulating factor-1 receptor, also known as M-CSFR / CD115) at the surface of hematopoietic stem cells and myelomonocytic cells. Two CSF-1 R ligands have been identified, CSF-1 $1^{73}$ and interleukin-34 (IL-34). ${ }^{74}$ IL-34 directs the differentiation of myeloid cells in the skin epidermis and central nervous system. ${ }^{75}$ CSF-1 is a monocytic lineage-specific cytokine that directly acts on a hematopoietic stem cell in the bone marrow 
Box 2 Deregulated interplay between GATA-1, HSP70 and caspases as a pathogenic mechanism of anemia in myelodysplastic syndromes (MDS) and $\beta$-thalassaemia

MDS are clonal disorders of the HSC in which ineffective hematopoiesis is responsible for peripheral blood cytopenias. Anemia is the consequence of a dyserythropoiesis that associates defective maturation and excessive apoptosis of erythroid precursors. The decreased GATA-1 expression observed in MDS erythroblasts correlates with a defect of HSP70 accumulation in erythroblast nucleus. GATA-1 expression can be restored by addition of pan-caspase inhibitors to erythroid cultures and erythroid differentiation is restored by expression of a mutated GATA-1 that cannot be cleaved by caspases or a mutated HSP70 targeted to the cell nucleus. ${ }^{44}$ It remains to be determined if defective Epo signaling is responsible for the abnormal shuttling of HSP70 to the nucleus or other pathways that regulate HSP70 localization are altered as a consequence of somatic mutations that accumulate in the HSC. Of note, caspase inhibition does not restore erythroid colony formation in early stage MDS, possibly because it blocks erythroid differentiation. ${ }^{45}$ In $\beta$-thalassaemia, HSP70 is sequestrated in the cytoplasm as it interacts with free $a$-globin chains of hemoglobin that accumulate as a consequence of the quantitative defect in the synthesis of $\beta$-globin chains. Again, the maturation of human $\beta$-thalassaemia major erythroblasts with a nuclear targeted HSP70 or a mutated GATA-1 that resists to caspase-3-mediated cleavage restores terminal erythroid maturation. ${ }^{46}$ In these two diseases, alteration of the GATA-1/ HSP70 interplay suggests therapeutic approaches that could restore the nucleocytoplasmic shuttling of HSP70.

to instruct a change of cell fate through activation of the endogenous Ets family transcription factor PU.1. ${ }^{76}$ Monocytes develop from HSCs via several commitment steps and intermediate progenitor stages that pass through the CMP, the GMP, and the macrophage/dendritic cell progenitor stages (Figure 1). PU.1 controls cell fate decisions by engaging in antagonistic interactions with other transcription factors, for example, with GATA-1 to shut down the MK/erythroid pathway, with GATA-2 to inhibit mast cell development, and with C/EBPa to block granulocytic differentiation. ${ }^{77}$ An official nomenclature subdivides mature monocytes into subsets with a suspected gradual developmental relationship between them. ${ }^{78}$ Over one billion monocytes are produced daily, with a fraction differentiating into macrophages while the others are deleted through a process that may involve the Fas pathway as spontaneous monocyte apoptosis in culture is inhibited by neutralizing antibodies to the death receptor Fas or its cognate ligand FasL ${ }^{79}$ and mice deficient in Fas display increased numbers of circulating monocytes. ${ }^{80}$

In some tissues such the epidermis (Langerhans cells) and the brain (microglia), macrophages derive from embryonic progenitors and self-maintain by local proliferation during adulthood with no or minimal input from circulating monocytes. ${ }^{81}$ In other tissues such as intestinal lamina propria (LP) and dermis, macrophages are replaced from monocytes and many other tissue-resident macrophages reflect an intermediate situation. ${ }^{82}$ Monocyte recruitment might occur under conditions of stress and inflammation that deplete the local population and also under homeostatic conditions to maintain the pool of macrophages in a given tissue when local self-renewal capacity becomes gradually exhausted with age. $^{81}$

In ex vivo culture, CSF-1-induced differentiation of monocytes into macrophages is associated with caspase activation in the absence of any cell death (Figure 1, 2c and 3c, Table 1), ${ }^{83}$ and this differentiation can be prevented by the pan-caspase inhibitor Z-VAD-fmk or expression of the viral pan-caspase inhibitor p35, or overexpression of the anti-apoptotic protein $\mathrm{Bcl}-2$. Caspase-8 deletion in mouse bone marrow cells also results in arrest of monocyte differentiation into macrophages. ${ }^{84}$ Caspase activation is not detected when circulating monocyte differentiation is induced by granulocyte macrophage colony-stimulating factor (GMCSF). CSF-1 and GM-CSF are the apex macrophage survival cytokines, with a strong role of GM-CSF in the function of alveolar macrophages and a broader effect of CSF-1. It was therefore paradoxical to detect caspase activation in monocytes treated with a cytokine that is essential for their survival.

CSF-1 interaction with CSF-1 $\mathrm{R}$ at the surface of human and murine peripheral blood monocytes in culture provokes the oscillatory activation of phosphatidylinositol-3-kinase and the kinase AKT (Figure 3c). ${ }^{85}$ After several waves of activation, within 2-3 days, a molecular platform is generated. This platform includes the adaptor protein FADD (Fas-associated death domain), RIPK1 (receptor-interacting serine/threonineprotein kinase 1), FLIP (cellular FLICE inhibitory protein) and procaspase-8 (Figure 3c). ${ }^{86}$ The formation of this platform and the subsequent activation of caspase- 8 may not require a death receptor as it is not prevented by the expression of a dominant negative mutant of FADD that cannot interact with death receptors. ${ }^{86}$ Active caspase-8 may directly cleave RIPK1, which turns down NF-KB activity (Figure 3c). ${ }^{86}$ Caspase-8 also activates downstream caspase-3 and caspase-7 that cleave a series of selected substrates. Identified targets of caspases in CSF-1-treated monocytes include nucleophosmin (NPM1), the serine/threonine-protein kinase PAK-2 (p21-activated kinase 2), a-tubulin, PAI-2 (plasminogen activator inhibitor-2), several mRNA binding proteins of the hnRNP family ( $\mathrm{H}$ and $\mathrm{C}$ ) and vinculin (Table 1). ${ }^{87}$ Several of these targets are involved in cytoskeletal regulation, suggesting a role of their proteolysis in the cytoskeleton reorganization associated with differentiation. Many other typical caspase targets in cells undergoing apoptosis are not cleaved, phosphatidylserine is not exposed at the cell surface, and no DNA fragmentation is detected. ${ }^{83,87}$

The tight regulation of the proteolytic process associated with differentiation is illustrated by the proteolysis of NPM1, a ubiquitously and abundantly expressed 38-kDa 
phosphoprotein that shuttles between the granular region of the nucleolus and the cytoplasm, especially during the $\mathrm{S}$ phase of the cell cycle. ${ }^{88}$ This chaperone protein and transcription co-regulator is a caspase substrate in cells undergoing apoptosis. $^{88}$ In CSF-1 treated monocytes, caspase-7 cleaves NPM1 at D213 to generate a $30-\mathrm{kDa}$ $\mathrm{N}$-terminal fragment, and the protein is further cleaved into a $20-k D a$ fragment by cathepsin B. ${ }^{89}$ NPM1 fragments contribute to the limited motility, migration and phagocytosis capabilities of resting macrophage and the proteolysis of NPM1 by caspase-7 and cathepsin B participates in the establishment of a mature macrophage phenotype. TLR4mediated activation of macrophages inhibits the proteolytic processes and restores expression of the full-length protein that negatively regulates the transcription of cytokines genes implicated in inflammation. In mice with heterozygous NPM1 gene deletion, cytokine production in response to lipopolysaccharide is dramatically enhanced. ${ }^{89}$

Macrophage polarization plays an important role in the pathogenesis of diverse human diseases. ${ }^{90}$ In a bleomycininduced lung fibrosis model, a caspase inhibitory molecule was shown to prevent the development of lung fibrosis, ${ }^{91}$ but additional studies are needed to determine if a change in the polarization of lung macrophages account for this effect.

In addition to activating caspases, engagement of CSF-1 $\mathrm{R}$ in monocytes elicits typical autophagy. ${ }^{92-94}$ In the absence of ATG7, differentiation of monocytes into macrophages is severely impaired with perturbed acquisition of specific macrophage functions such as bacteria phagocytosis. ${ }^{93}$ On the contrary to caspase activation however, accumulation of LC3-II, increased expression of SQSTM1/p62 and enhanced activity of cathepsins that characterize autophagy are observed in monocytes treated with GM-CSF. ${ }^{95}$

Many stress pathways induce autophagy, and apoptosis within the same cell, usually in a sequence in which autophagy precedes apoptosis. ${ }^{96}$ These processes cross-regulate each other, mostly in an inhibitory manner, that is, autophagy blocks the induction of apoptosis until caspase activation shuts off the autophagic process. Mitophagy and the interaction of sequestosome 1 (SQSTM1 or p62) with ubiquitylated proteins are two ways for autophagy to prevent apoptosis, but the dialogue between autophagy and caspase-dependent cell death is context-dependent. CSF1-induced differentiation of monocytes into macrophages may represent a unique model in which autophagy efficiently restrains caspase activation to prevent cell death. Both ATG5 and SQSTM1, which are involved in autophagy, were co-localized with caspase-8, FADD, FLIP and RIPK1, suggesting that initiation of autophagy and caspase activation could occur in the same cell compartment. $^{97}$

Monocytes are key actors of innate and adaptive immune responses through the production of IL-1 $\beta$. The proteolytic activating cleavage of pro-IL $1 \beta$ is most commonly executed by caspase- 1 whose activity is controlled by the formation of the inflammasome. Typically, this process leads to pyroptosis through caspase-1-mediated cleavage of the effector molecule GSDMD (Gasdermin-D). Human monocytes can secrete mature IL-1 $\beta$ in response to lipopolysaccharide through an alternative inflammasome activation that relies on
TLR4-TRIF-RIPK1-FADD-CASP8 to propagate activation to NLRP3, a pathway that does not lead to cell death. ${ }^{15}$

\section{Active Caspase-3 in Mast Cell Granules}

Active caspase- 3 was recently identified in human mast cells in the absence of apoptosis. GMP give rise to basophil-mast cell progenitors (BMCP, CD34 ${ }^{+}, \mathrm{CD}_{13}^{+}, \mathrm{FccRl}^{-}, \mathrm{KIT}^{+}$) in the bone marrow. These progenitors circulate in the peripheral blood as agranular mononuclear leukocytes and complete their maturation into peripheral tissues where they acquire phenotypic diversity. SCF is the most important cytokine involved in mast cell development, driving their homing, proliferation, survival and differentiation. Different mast cell phenotypes finally develop in vascular tissues and organs, containing tryptase alone or both tryptase and chymase along with other proteases in their lysosome-like secretory granules. ${ }^{98}$ These cells are important effector cells of the immune system that, like many other bone-marrow-derived hematopoietic cells, die through a caspase-dependent apoptotic process. ${ }^{99,100}$ Enzymatically active caspase-3 was not detected in BMCPs but appeared to accumulate during the process of mast cell maturation (Table 1). The enzyme was located in subcellular fractions containing secretory granulelocalized proteases and rapidly released into the cytosolic compartment after permeabilization of the secretory granules upon mast cell activation. ${ }^{101,102}$

\section{Concluding Remarks}

Non-apoptotic functions of caspases contribute to the differentiation of erythroid cells, the maturation of proplatelets, the release of platelets and the functions of mast cells and CSF-1 induced macrophages, suggesting fine-tuned adaptive processes triggered by cytokines and chemokines. A nonapoptotic function of caspase-3 was also detected in bone marrow stromal stem cells ${ }^{103}$ and hematopoietic stem cells, ${ }^{104}$ suggesting that this enzyme could be a gatekeeper of stem cell functions. The loss of caspase- 3 favors HSC proliferation while decreasing their differentiation, in part through modifying their response to exogenous signals provided by their environment, ${ }^{104}$ a phenotype partially rescued by the deletion of p21 $1^{\text {cip } 1 / \text { waf1 } 105}$ Caspase-2 knock-out also affects mouse HSC behavior by promoting their myeloid differentiation but the molecular pathway involved remain unknown. ${ }^{106}$ The relevance of these observations in healthy and diseased human HSC his unclear.

The non-apoptotic functions of caspases raise compelling questions of how the activity of these death-associated enzymes is controlled to maintain cell integrity. Much of the regulation of apoptotic functions of caspases may be carried out by IAPs, but there is still little evidence that these ubiquitin ligases are involved in the regulation of their non-apoptotic functions. ${ }^{107}$ Some cells resist caspase-mediated cell death by sequestering caspase activity in specific subcellular regions, as described in Drosophila spermatids, ${ }^{108}$ insect neuronal dendrites, ${ }^{109}$ and megakaryocytes. ${ }^{55}$ Caspase activation can also be very transient and coordinated with the chaperoning of key proteins for cell survival and differentiation, as observed in the erythroid lineage. Finally, 
the biochemical mechanisms leading to caspase activation could differ during differentiation and cell death, for example, conformational changes without cleavage could activate these enzymes. ${ }^{110}$ The dynamics of caspase activation in differentiating cells is still poorly understood. While the signaling cascade activated by CSF-1 in monocytes has been partially identified, going through waves of $\mathrm{Pl}-3 \mathrm{~K}$ signaling with increasing duration and amplitude to finally promote the formation of a cytosolic multimolecular platform in which caspase-8 is recruited and activated, it remains unclear how TPO and Epo activate non-apoptotic caspases in differentiating MK and basophilic erythroblasts respectively. With some exceptions, the contribution of most of the caspase substrates cleaved in these non-apoptotic settings remains poorly explored. Finally, with the ermergence of clinically tested caspase inhibitors, ${ }^{111}$ a central question will be to determine if these enzymes could be therapeutically manipulated to restore or inhibit specific differentiation pathway, for example, to modulate immune cell polarization.

\section{Conflict of Interest}

The authors declare no conflict of interest.

Acknowledgements. The team is supported by grants from the Ligue Nationale Contre le Cancer (équipe labellisée), agence nationale de la recherche (Molecular Medicine in Oncology program), and the Institut National du Cancer.

1. Orkin SH, Zon LI. Hematopoiesis: an evolving paradigm for stem cell biology. Cell 2008; 132: $631-644$

2. Notta F, Zandi S, Takayama N, Dobson S, Gan OI, Wilson G et al. Distinct routes of lineage development reshape the human blood hierarchy across ontogeny. Science 2016; 351 : aab2116.

3. Perie L, Duffy KR, Kok L, de Boer RJ, Schumacher TN. The branching point in erythromyeloid differentiation. Cell 2015; 163: 1655-1662.

4. Paul F, Arkin Y, Giladi A, Jaitin DA, Kenigsberg E, Keren-Shaul $H$ et al. Transcriptional heterogeneity and lineage commitment in myeloid progenitors. Cell 2015; 163: 1663-1677.

5. Drissen R, Buza-Vidas N, Woll P, Thongjuea S, Gambardella A, Giustacchini A et al. Distinct myeloid progenitor-differentiation pathways identified through single-cell RNA sequencing. Nat Immunol 2016; 17: 666-676.

6. Pozzesi N, Fierabracci A, Liberati AM, Martelli MP, Ayroldi E, Riccardi C et al. Role of caspase-8 in thymus function. Cell Death Differ 2014; 21: 226-233.

7. Opferman JT. Apoptosis in the development of the immune system. Cell Death Differ 2008; 15: 234-242.

8. Lu EP, McLellan M, Ding L, Fulton R, Mardis ER, Wilson RK et al. Caspase-9 is required for normal hematopoietic development and protection from alkylator-induced DNA damage in mice. Blood 2014; 124: 3887-3895.

9. Ben Baruch-Morgenstern N, Shik D, Moshkovits I, Itan M, Karo-Atar D, Bouffi C et al. Paired immunoglobulin-like receptor $A$ is an intrinsic, self-limiting suppressor of IL-5-induced eosinophil development. Nat Immunol 2014; 15: 36-44.

10. Geering B, Simon HU. Peculiarities of cell death mechanisms in neutrophils. Cell Death Differ 2011; 18: 1457-1469.

11. Bratosin D, Estaquier J, Petit F, Arnoult D, Quatannens B, Tissier JP et al. Programmed cell death in mature erythrocytes: a model for investigating death effector pathways operating in the absence of mitochondria. Cell Death Differ 2001; 8: 1143-1156.

12. Lang E, Lang F. Mechanisms and pathophysiological significance of eryptosis, the suicidal erythrocyte death. Semin Cell Dev Biol 2015; 39: 35-42.

13. Mason KD, Carpinelli MR, Fletcher JI, Collinge JE, Hilton AA, Ellis S et al. Programmed anuclear cell death delimits platelet life span. Cell 2007; 128: 1173-1186.

14. Rickard JA, O'Donnell JA, Evans JM, Lalaoui N, Poh AR, Rogers T et al. RIPK1 regulates RIPK3-MLKL-driven systemic inflammation and emergency hematopoiesis. Cell 2014; 157: 1175-1188.

15. Gaidt MM, Ebert TS, Chauhan D, Schmidt T, Schmid-Burgk JL, Rapino F et al. Human monocytes engage an alternative inflammasome pathway. Immunity 2016; 44: 833-846.

16. Croker BA, Silke J, Gerlic M. Fight or flight: regulation of emergency hematopoiesis by pyroptosis and necroptosis. Curr Opin Hematol 2015; 22: 293-301.

17. Basiorka AA, McGraw KL, Eksioglu EA, Chen X, Johnson J, Zhang L et al. The NLRP3 Inflammasome functions as a driver of the myelodysplastic syndrome phenotype. Blood 2016; 128: 2960-2975.
18. Chun HJ, Zheng L, Ahmad M, Wang J, Speirs CK, Siegel RM et al. Pleiotropic defects in lymphocyte activation caused by caspase-8 mutations lead to human immunodeficiency. Nature 2002; 419: 395-399.

19. Woo M, Hakem R, Furlonger C, Hakem A, Duncan GS, Sasaki T et al. Caspase-3 regulates cell cycle in B cells: a consequence of substrate specificity. Nat Immunol 2003; 4: 1016-1022.

20. Su H, Bidere N, Zheng L, Cubre A, Sakai K, Dale J et al. Requirement for caspase-8 in NF-KB activation by antigen receptor. Science 2005; 307: 1465-1468.

21. Gregory CJ, Eaves AC. Three stages of erythropoietic progenitor cell differentiation distinguished by a number of physical and biologic properties. Blood 1978; 51: 527-537.

22. Chen K, Liu J, Heck S, Chasis JA, An X, Mohandas N. Resolving the distinct stages in erythroid differentiation based on dynamic changes in membrane protein expression during erythropoiesis. Proc Natl Acad Sci USA 2009; 106: 17413-17418.

23. Aispuru GR, Aguirre MV, Aquino-Esperanza JA, Lettieri CN, Juaristi JA, Brandan NC. Erythroid expansion and survival in response to acute anemia stress: the role of EPO receptor, GATA-1, Bcl-xL and caspase-3. Cell Biol Int 2008; 32: 966-978.

24. Carlile GW, Smith DH, Wiedmann M. Caspase-3 has a nonapoptotic function in erythroid maturation. Blood 2004; 103: 4310-4316.

25. Kolbus A, Pilat S, Husak Z, Deiner EM, Stengl G, Beug H et al. Raf-1 antagonizes erythroid differentiation by restraining caspase activation. J Exp Med 2002; 196: 1347-1353.

26. Zermati Y, Garrido C, Amsellem S, Fishelson S, Bouscary D, Valensi F et al. Caspase activation is required for terminal erythroid differentiation. J Exp Med 2001; 193: 247-254.

27. Boehm D, Mazurier C, Giarratana MC, Darghouth D, Faussat AM, Harmand L et al. Caspase-3 is involved in the signalling in erythroid differentiation by targeting late progenitors. PLOS ONE 2013; 8: e62303.

28. Kuida K, Zheng TS, Na S, Kuan C, Yang D, Karasuyama H et al. Decreased apoptosis in the brain and premature lethality in CPP32-deficient mice. Nature 1996; 384: 368-372.

29. Le DA, Wu Y, Huang Z, Matsushita K, Plesnila N, Augustinack JC et al. Caspase activation and neuroprotection in caspase-3- deficient mice after in vivo cerebral ischemia and in vitro oxygen glucose deprivation. Proc Natl Acad Sci USA 2002; 99: 15188-15193.

30. Dasse E, Bridoux L, Baranek T, Lambert E, Salesse S, Sowa ML et al. Tissue inhibitor of metalloproteinase-1 promotes hematopoietic differentiation via caspase-3 upstream the MEKK1/MEK6/p38alpha pathway. Leukemia 2007; 21: 595-603.

31. Gabet AS, Coulon S, Fricot A, Vandekerckhove J, Chang Y, Ribeil JA et al. Caspaseactivated ROCK-1 allows erythroblast terminal maturation independently of cytokineinduced Rho signaling. Cell Death Differ 2011; 18: 678-689.

32. Lui JC, Kong SK. Erythropoietin activates caspase-3 and downregulates CAD during erythroid differentiation in TF-1 cells - a protection mechanism against DNA fragmentation. FEBS Lett 2006; 580: 1965-1970.

33. Naarmann-de Vries IS, Urlaub H, Ostareck DH, Ostareck-Lederer A. Caspase-3 cleaves hnRNP K in erythroid differentiation. Cell Death Dis 2013; 4: e548.

34. Ji P. New insights into the mechanisms of mammalian erythroid chromatin condensation and enucleation. Int Rev Cell Mol Biol 2015; 316: 159-182.

35. Kawane K, Fukuyama H, Kondoh G, Takeda J, Ohsawa Y, Uchiyama Y et al. Requirement of DNase II for definitive erythropoiesis in the mouse fetal liver. Science 2001; 292 . 1546-1549.

36. Hattangadi SM, Martinez-Morilla S, Patterson HC, Shi J, Burke K, Avila-Figueroa A et al. Histones to the cytosol: exportin 7 is essential for normal terminal erythroid nuclear maturation. Blood 2014; 124: 1931-1940.

37. Baron MH, Barminko J. Chromatin condensation and enucleation in red blood cells: an open question. Dev Cell 2016; 36: 481-482.

38. Zhao B, Mei Y, Schipma MJ, Roth EW, Bleher R, Rappoport JZ et al. Nuclear condensation during mouse erythropoiesis requires caspase-3-mediated nuclear opening. Dev Cell 2016; 36: 498-510.

39. Yoshida H, Kawane K, Koike M, Mori Y, Uchiyama Y, Nagata S. Phosphatidylserinedependent engulfment by macrophages of nuclei from erythroid precursor cells. Nature 2005; 437: 754-758.

40. De Maria R, Testa U, Luchetti L, Zeuner A, Stassi G, Pelosi E et al. Apoptotic role of Fas/Fas ligand system in the regulation of erythropoiesis. Blood 1999; 93: 796-803.

41. Pevny L, Simon MC, Robertson E, Klein WH, Tsai SF, D'Agati V et al. Erythroid differentiation in chimaeric mice blocked by a targeted mutation in the gene for transcription factor GATA-1. Nature 1991; 349: 257-260.

42. Gregory T, Yu C, Ma A, Orkin SH, Blobel GA, Weiss MJ. GATA-1 and erythropoietin cooperate to promote erythroid cell survival by regulating bcl-xL expression. Blood 1999; 94: 87-96.

43. Ribeil JA, Zermati Y, Vandekerckhove J, Cathelin S, Kersual J, Dussiot M et al. Hsp70 regulates erythropoiesis by preventing caspase-3-mediated cleavage of GATA-1. Nature 2007; 445: 102-105.

44. Frisan E, Vandekerckhove J, de Thonel A, Pierre-Eugene C, Sternberg A, Arlet JB et al Defective nuclear localization of Hsp70 is associated with dyserythropoiesis and GATA-1 cleavage in myelodysplastic syndromes. Blood 2012; 119: 1532-1542.

45. Bouscary D, Chen YL, Guesnu M, Picard F, Viguier F, Lacombe C et al. Activity of the caspase-3/CPP32 enzyme is increased in "early stage" myelodysplastic syndromes with excessive apoptosis, but caspase inhibition does not enhance colony formation in vitro. Experimental hematology 2000; 28: 784-791.

46. Arlet JB, Ribeil JA, Guillem F, Negre O, Hazoume A, Marcion G et al. HSP70 sequestration by free alpha-globin promotes ineffective erythropoiesis in beta-thalassaemia. Nature 2014; 514: 242-246. 
47. Whyatt $D$, Lindeboom $F$, Karis A, Ferreira R, Milot E, Hendriks $R$ et al. An intrinsic but cellnonautonomous defect in GATA-1-overexpressing mouse erythroid cells. Nature 2000; 406 : 519-524.

48. de Thonel A, Vandekerckhove J, Lanneau D, Selvakumar S, Courtois G, Hazoume A et al. HSP27 controls GATA-1 protein level during erythroid cell differentiation. Blood 2010; 116: 85-96.

49. Kile BT. The role of apoptosis in megakaryocytes and platelets. Br J Haematol 2014; 165 : 217-226.

50. Zauli G, Vitale M, Falcieri E, Gibellini D, Bassini A, Celeghini C et al. In vitro senescence and apoptotic cell death of human megakaryocytes. Blood 1997; 90: 2234-2243.

51. Ogilvy S, Metcalf D, Print CG, Bath ML, Harris AW, Adams JM. Constitutive Bcl-2 expression throughout the hematopoietic compartment affects multiple lineages and enhances progenitor cell survival. Proc Natl Acad Sci USA 1999; 96: 14943-14948.

52. Bouillet $P$, Metcalf D, Huang DC, Tarlinton DM, Kay TW, Kontgen F et al. Proapoptotic Bcl-2 relative Bim required for certain apoptotic responses, leukocyte homeostasis, and to preclude autoimmunity. Science 1999; 286: 1735-1738.

53. Kaluzhny Y, Yu G, Sun S, Toselli PA, Nieswandt B, Jackson CW et al. BclxL overexpression in megakaryocytes leads to impaired platelet fragmentation. Blood 2002; 100: 1670-1678.

54. Clarke MC, Savill J, Jones DB, Noble BS, Brown SB. Compartmentalized megakaryocyte death generates functional platelets committed to caspase-independent death. J Cell Biol 2003; 160: 577-587.

55. De Botton S, Sabri S, Daugas E, Zermati Y, Guidotti JE, Hermine 0 et al. Platelet formation is the consequence of caspase activation within megakaryocytes. Blood 2002; 100: 1310-1317.

56. Houwerzijl EJ, Blom NR, van der Want JJ, Vellenga E, de Wolf JT. Megakaryocytic dysfunction in myelodysplastic syndromes and idiopathic thrombocytopenic purpura is in part due to different forms of cell death. Leukemia 2006; 20: 1937-1942.

57. Morison IM, Cramer Borde EM, Cheesman EJ, Cheong PL, Holyoake AJ, Fichelson S et al. A mutation of human cytochrome $c$ enhances the intrinsic apoptotic pathway but causes only thrombocytopenia. Nat Genet 2008; 40: 387-389.

58. White MJ, Schoenwaelder SM, Josefsson EC, Jarman KE, Henley KJ, James C et al. Caspase- 9 mediates the apoptotic death of megakaryocytes and platelets, but is dispensable for their generation and function. Blood 2012; 119: 4283-4290.

59. Debrincat MA, Josefsson EC, James C, Henley KJ, Ellis S, Lebois M et al. Mcl-1 and Bcl-x (L) coordinately regulate megakaryocyte survival. Blood 2012; 119: 5850-5858.

60. Josefsson EC, James C, Henley KJ, Debrincat MA, Rogers KL, Dowling MR et al. Megakaryocytes possess a functional intrinsic apoptosis pathway that must be restrained to survive and produce platelets. J Exp Med 2011; 208: 2017-2031.

61. Kodama T, Hikita H, Kawaguchi T, Shigekawa M, Shimizu S, Hayashi Y et al. Mcl-1 and $\mathrm{Bcl}-\mathrm{xL}$ regulate Bak/Bax-dependent apoptosis of the megakaryocytic lineage at multistages. Cell Death Differ 2012; 19: 1856-1869.

62. Kodama T, Takehara T, Hikita H, Shimizu S, Shigekawa M, Li W et al. BH3-only activator proteins Bid and Bim are dispensable for Bak/Bax-dependent thrombocyte apoptosis induced by $\mathrm{Bcl}-\mathrm{xL}$ deficiency: molecular requisites for the mitochondrial pathway to apoptosis in platelets. J Biol Chem 2011; 286: 13905-13913.

63. Melloni E, Secchiero P, Celeghini C, Campioni D, Grill V, Guidotti L et al. Functiona expression of TRAIL and TRAIL-R2 during human megakaryocytic development. J Cell Physiol 2005; 204: 975-982

64. Yang L, Wang L, Zhao CH, Zhu XJ, Hou Y, Jun P et al. Contributions of TRAlL-mediated megakaryocyte apoptosis to impaired megakaryocyte and platelet production in immune thrombocytopenia. Blood 2010; 116: 4307-4316.

65. Josefsson EC, Burnett DL, Lebois M, Debrincat MA, White MJ, Henley KJ et al. Platelet production proceeds independently of the intrinsic and extrinsic apoptosis pathways. Nat Commun 2014; 5: 3455

66. Morishima N, Nakanishi K. Proplatelet formation in megakaryocytes is associated with endoplasmic reticulum stress. Genes Cells 2016; 21: 798-806.

67. Abd-Elrahman I, Deutsch V, Pick M, Kay S, Neuman T, Perlman R et al. Differential regulation of the apoptotic machinery during megakaryocyte differentiation and platelet production by inhibitor of apoptosis protein Livin. Cell Death Dis 2013; 4: e937.

68. Nishimura S, Nagasaki M, Kunishima S, Sawaguchi A, Sakata A, Sakaguchi $\mathrm{H}$ et al. IL-1alpha induces thrombopoiesis through megakaryocyte rupture in response to acute platelet needs. J Cell Biol 2015; 209: 453-466.

69. Wilson WH, O'Connor OA, Czuczman MS, LaCasce AS, Gerecitano JF, Leonard JP et al. Navitoclax, a targeted high-affinity inhibitor of BCL-2, in lymphoid malignancies: a phase 1 dose-escalation study of safety, pharmacokinetics, pharmacodynamics, and antitumour activity. Lancet Oncol 2010; 11: 1149-1159.

70. Souers AJ, Leverson JD, Boghaert ER, Ackler SL, Catron ND, Chen J et al. ABT-199, a potent and selective BCL-2 inhibitor, achieves antitumor activity while sparing platelets. Nat Med 2013; 19: 202-208.

71. Schoenwaelder SM, Yuan Y, Josefsson EC, White MJ, Yao Y, Mason KD et al. Two distinct pathways regulate platelet phosphatidylserine exposure and procoagulant function. Blood 2009; 114: 663-666.

72. Kerrigan SW, Gaur M, Murphy RP, Shattil SJ, Leavitt AD. Caspase-12: a developmental link between G-protein-coupled receptors and integrin alphallbbeta3 activation. Blood 2004; 104: 1327-1334

73. Kawasaki ES, Ladner MB, Wang AM, Van Arsdell J, Warren MK, Coyne MY et al. Molecular cloning of a complementary DNA encoding human macrophage-specific colony-stimulating factor (CSF-1). Science 1985; 230: 291-296.
74. Lin H, Lee E, Hestir K, Leo C, Huang M, Bosch E et al. Discovery of a cytokine and its receptor by functional screening of the extracellular proteome. Science 2008; 320: 807-811.

75. Wang Y, Szretter KJ, Vermi W, Gilfillan S, Rossini C, Cella M et al. IL-34 is a tissuerestricted ligand of CSF1R required for the development of Langerhans cells and microglia. Nat Immunol 2012; 13: 753-760.

76. Mossadegh-Keller N, Sarrazin S, Kandalla PK, Espinosa L, Stanley ER, Nutt SL et al. MCSF instructs myeloid lineage fate in single haematopoietic stem cells. Nature 2013; 497: 239-243.

77. Auffray C, Sieweke MH, Geissmann F. Blood monocytes: development, heterogeneity, and relationship with dendritic cells. Ann Rev Immunol 2009; 27: 669-692.

78. Wong KL, Tai JJ, Wong WC, Han H, Sem X, Yeap WH et al. Gene expression profiling reveals the defining features of the classical, intermediate, and nonclassical human monocyte subsets. Blood 2011; 118: e16-e31.

79. Kiener PA, Davis PM, Starling GC, Mehlin C, Klebanoff SJ, Ledbetter JA et al. Differential induction of apoptosis by Fas-Fas ligand interactions in human monocytes and macrophages. J Exp Med 1997; 185: 1511-1516.

80. Brown NJ, Hutcheson J, Bickel E, Scatizzi JC, Albee LD, Haines GK 3rd et al. Fas death receptor signaling represses monocyte numbers and macrophage activation in vivo. J Immunol 2004; 173: 7584-7593.

81. Gentek R, Molawi K, Sieweke MH. Tissue macrophage identity and self-renewal. Immunol Rev 2014; 262: 56-73.

82. Tamoutounour S, Guilliams M, Montanana Sanchis F, Liu H, Terhorst D, Malosse C et al. Origins and functional specialization of macrophages and of conventional and monocytederived dendritic cells in mouse skin. Immunity 2013; 39: 925-938.

83. Sordet $\mathrm{O}$, Rebe $\mathrm{C}$, Plenchette $\mathrm{S}$, Zermati $\mathrm{Y}$, Hermine $\mathrm{O}$, Vainchenker $\mathrm{W}$ et al. Specific involvement of caspases in the differentiation of monocytes into macrophages. Blood 2002; 100: 4446-4453.

84. Kang TB, Ben-Moshe T, Varfolomeev EE, Pewzner-Jung Y, Yogev N, Jurewicz A et al. Caspase-8 serves both apoptotic and nonapoptotic roles. J Immunol 2004; 173 : 2976-2984

85. Jacquel A, Benikhlef N, Paggetti J, Lalaoui N, Guery L, Dufour EK et al. Colony-stimulating factor-1-induced oscillations in phosphatidylinositol-3 kinase/AKT are required for caspase activation in monocytes undergoing differentiation into macrophages. Blood 2009; 114 : 3633-3641.

86. Rebe C, Cathelin S, Launay S, Filomenko R, Prevotat L, L'Ollivier C et al. Caspase-8 prevents sustained activation of NF-kappaB in monocytes undergoing macrophagic differentiation. Blood 2007; 109: 1442-1450.

87. Cathelin S, Rebe C, Haddaoui L, Simioni N, Verdier F, Fontenay M et al. Identification of proteins cleaved downstream of caspase activation in monocytes undergoing macrophage differentiation. J Biol Chem 2006; 281: 17779-17788.

88. Chou CC, Yung BY. Increased stability of nucleophosmin/B23 in anti-apoptotic effect of ras during serum deprivation. Mol Pharmacol 2001; 59: 38-45.

89. Guery L, Benikhlef N, Gautier T, Paul C, Jego G, Dufour E et al. Fine-tuning nucleophosmin in macrophage differentiation and activation. Blood 2011; 118: 4694-4704.

90. Sica A, Mantovani A. Macrophage plasticity and polarization: in vivo veritas. J Clin Invest 2012; 122: 787-795.

91. Wang R, Ibarra-Sunga O, Verlinski L, Pick R, Uhal BD. Abrogation of bleomycin-induced epithelial apoptosis and lung fibrosis by captopril or by a caspase inhibitor. Am J Physiol Lung Cell Mol Physiol 2000; 279: L143-L151.

92. Jacquel A, Obba S, Boyer L, Dufies M, Robert G, Gounon P et al. Autophagy is required for CSF-1-induced macrophagic differentiation and acquisition of phagocytic functions. Blood 2012; 119: 4527-4531.

93. Jacquel A, Obba S, Solary E, Auberger P. Proper macrophagic differentiation requires both autophagy and caspase activation. Autophagy 2012; 8: 1141-1143.

94. Obba S, Hizir Z, Boyer L, Selimoglu-Buet D, Pfeifer A, Michel G et al. The PRKAA1/ AMPKalpha1 pathway triggers autophagy during CSF1-induced human monocyte differentiation and is a potential target in CMML. Autophagy 2015; 11: 1114-1129.

95. Zhang Y, Morgan MJ, Chen K, Choksi S, Liu ZG. Induction of autophagy is essential for monocyte-macrophage differentiation. Blood 2012; 119: 2895-2905.

96. Marino G, Niso-Santano M, Baehrecke EH, Kroemer G. Self-consumption: the interplay of autophagy and apoptosis. Nat Rev Mol Cell Biol 2014; 15: 81-94.

97. Pan JA, Ullman E, Dou Z, Zong WX. Inhibition of protein degradation induces apoptosis through a microtubule-associated protein 1 light chain 3-mediated activation of caspase-8 at intracellular membranes. Mol Cell Biol 2011; 31: 3158-3170.

98. Marshall JS. Mast-cell responses to pathogens. Nat Rev Immunol 2004; 4: 787-799.

99. Cohen-Saidon C, Carmi I, Keren A, Razin E. Antiapoptotic function of Bcl-2 in mast cells is dependent on its association with heat shock protein 90beta. Blood 2006; 107: 1413-1420.

100. Marsden VS, Kaufmann T, O'Reilly L A, Adams JM, Strasser A. Apaf-1 and caspase- 9 are required for cytokine withdrawal-induced apoptosis of mast cells but dispensable for their functional and clonogenic death. Blood 2006; 107: 1872-1877.

101. Garcia-Faroldi G, Melo FR, Ronnberg E, Grujic M, Pejler G. Active caspase-3 is stored within secretory compartments of viable mast cells. J Immunol 2013; 191: 1445-1452.

102. Zorn CN, Pardo J, Martin P, Kuhny M, Simon MM, Huber M. Secretory lysosomes of mouse mast cells store and exocytose active caspase-3 in a strictly granzyme B dependent manner. Eur J Immunol 2013; 43: 3209-3218. 
103. Miura M, Chen XD, Allen MR, Bi Y, Gronthos S, Seo BM et al. A crucial role of caspase- 3 in osteogenic differentiation of bone marrow stromal stem cells. J Clin Invest 2004; 114: 1704-1713.

104. Janzen V, Fleming HE, Riedt T, Karlsson G, Riese MJ, Lo Celso C et al. Hematopoietic stem cell responsiveness to exogenous signals is limited by caspase-3. Cell Stem Cell 2008; 2: 584-594.

105. Carrillo Garcia C, Riedt T, Li J, Dotten M, Brossart P, Janzen V. Simultaneous deletion of p21Cip1/Waf1 and caspase-3 accelerates proliferation and partially rescues the differentiation defects of caspase-3 deficient hematopoietic stem cells. PLOS ONE 2014; 9: e109266.

106. Dawar S, Lim Y, Puccini J, White M, Thomas P, Bouchier-Hayes L et al. Caspase-2-mediated cell death is required for deleting aneuploid cells. Oncogene 2016. (doi:10.1038/onc.2016.423).

107. Kuranaga E, Kanuka H, Tonoki A, Takemoto K, Tomioka T, Kobayashi M et al. Drosophila IKK-related kinase regulates nonapoptotic function of caspases via degradation of IAPs. Cell 2006; 126: 583-596.

108. Aram L, Braun T, Braverman C, Kaplan Y, Ravid L, Levin-Zaidman S et al. A Krebs cycle component limits caspase activation rate through mitochondrial surface restriction of $C R L$ activation. Dev Cell 2016; 37: 15-33.

109. Kuo CT, Zhu S, Younger S, Jan LY, Jan YN. Identification of E2/E3 ubiquitinating enzymes and caspase activity regulating Drosophila sensory neuron dendrite pruning. Neuron 2006; 51: 283-290.

110. Misra RS, Jelley-Gibbs DM, Russell JQ, Huston G, Swain SL, Budd RC. Effector CD4+ $T$ cells generate intermediate caspase activity and cleavage of caspase-8 substrates. J Immunol 2005; 174: 3999-4009.
111. MacKenzie SH, Schipper JL, Clark AC. The potential for caspases in drug discovery. Curr Opin Drug Discov Dev 2010; 13: 568-576.

112. Solier S, Sordet O, Kohn KW, Pommier Y. Death receptor-induced activation of the Chk2- and histone H2AX-associated DNA damage response pathways. Mol Cell Biol 2009; 29: 68-82.

113. Garcon L, Rivat C, James C, Lacout C, Camara-Clayette V, Ugo V et al. Constitutive activation of STAT5 and Bcl-xL overexpression can induce endogenous erythroid colony formation in human primary cells. Blood 2006; 108: 1551-1554.

114. Mori M, Uchida M, Watanabe T, Kirito K, Hatake K, Ozawa K et al. Activation of extracellular signal-regulated kinases ERK1 and ERK2 induces Bcl-xL up-regulation via inhibition of caspase activities in erythropoietin signaling. J Cell Physiol 2003; 195: 290-297.

115. Gregoli PA, Bondurant MC. The roles of $\mathrm{BCl}-\mathrm{X}(\mathrm{L})$ and apopain in the control of erythropoiesis by erythropoietin. Blood 1997; 90: 630-640.

116. Abutin RM, Chen J, Lung TK, Lloyd JA, Sawyer ST, Harada H. Erythropoietin-induced phosphorylation/degradation of BIM contributes to survival of erythroid cells. Exp Hematol 2009; 37: 151-158.

117. Dev A, Byrne SM, Verma R, Ashton-Rickardt PG, Wojchowski DM. Erythropoietin-directed erythropoiesis depends on serpin inhibition of erythroblast lysosomal cathepsins. J Exp Med 2013; 210: 225-232.

118. De Maria R, Zeuner A, Eramo A, Domenichelli C, Bonci D, Grignani F et al. Negative regulation of erythropoiesis by caspase-mediated cleavage of GATA-1. Nature 1999; 401: 489-493.

119. Koulnis M, Liu Y, Hallstrom K, Socolovsky M. Negative autoregulation by Fas stabilizes adult erythropoiesis and accelerates its stress response. PLOS ONE 2011; 6: e21192.

120. Zeuner A, Eramo A, Testa U, Felli N, Pelosi E, Mariani G et al. Control of erythroid cell production via caspase-mediated cleavage of transcription factor SCL/Tal-1. Cell Death Differ 2003; 10: 905-913. 